\title{
Correction to: The cost of lost productivity due to premature mortality associated with COVID-19: a Pan-European study
}

\author{
Paul Hanly $^{1}{ }^{1} \cdot$ Michelle Ahern $^{1} \cdot$ Linda Sharp ${ }^{2} \cdot$ Diana Ursul $^{1} \cdot$ Gerard Loughnane $^{1}$
}

Accepted: 17 September 2021 / Published online: 13 October 2021

c) Springer-Verlag GmbH Germany, part of Springer Nature 2021

\section{Correction to: The European Journal of Health Economics https://doi.org/10.1007/s10198-021-01351-8}

The author of the article would like to update the affiliation details of Diana Ursul,

The update affiliation details are as follow

\section{Dianna Dia}

National College of Ireland

ursul.diana@gmail.com

The original article has been updated.

Publisher's Note Springer Nature remains neutral with regard to jurisdictional claims in published maps and institutional affiliations.

Paul Hanly

paul.hanly@ncirl.ie

Michelle Ahern

Michelle.ahern@ncirl.ie

Linda Sharp

linda.sharp@ncl.ac.uk

Diana Ursul

ursul.diana@gmail.com

Gerard Loughnane

Gerard.Loughnane@ncirl.ie

1 National College of Ireland, Mayor Street, Dublin 1, Ireland

2 Newcastle University, Newcastle upon Tyne, UK 